\title{
Cancer Incidence and Mortality in Central Myanmar: Report of Nay Pyi Taw Population-Based Cancer Registry
}

\author{
Kaung Myat Shwe ${ }^{1 *}$, Soe Myat Win ${ }^{1}$, Aye Nyein Thant ${ }^{1}$, Aung Myo Sat Htay ${ }^{1}$, \\ Hlwan Moe Han', Naw Hsah Ka Paw
}

\begin{abstract}
Background: Cancer is a major public health problem in Myanmar, and cancer registration activities are currently underway through both hospital-based and population-based approaches. So far, there are no population-based cancer incidence and mortality estimates in the country. Methods: According to the 2014 census, the total population of Nay Pyi Taw Union Territory was 1,160,242 within the area of 70,571 $\mathrm{km}^{2}$. Nay Pyi Taw Cancer Registry team collected data of new cancer cases both actively and passively from all data sources in the region. The data were registered, updated, cross-checked, quality-assured, and analyzed in CanReg5. The results were presented as the number of cases by site, sex, and age, cumulative risk (CR), crude rate, age-specific, and age-standardized incidence rates (ASRs) per 100,000. Results: Total 5,952 new cancer cases and 1874 cancer deaths were recorded among the population of the Nay Pyi Taw Union Territory between 2013 and 2017. The age-standardized incidence rate for all cancer sites excluding nonmelanoma skin cancers in males was 125.9 and 107.3 for females. For both sexes combined, the most common cancers were lung $(14 \%)$, breast $(11.4 \%)$, liver $(10.2 \%)$, mouth and pharynx $(8.5 \%)$, and stomach cancers $(7.8 \%)$. In males, the most common were lung (18.1\%), liver (14.8\%), mouth and pharynx (13\%), stomach $(8.9 \%)$ and colon, rectum, and anus $(7.4 \%)$ cancers. In females, these were breast $(21.2 \%)$, cervix $(13.0 \%)$, lung $(10.3 \%)$, stomach $(6.9 \%)$ and colon, rectum, and anus (6.3\%) cancers. The most common cancer deaths were caused by liver (20.8\%), lung (15.7\%), mouth and pharynx $(9.3 \%)$, stomach $(7.5 \%)$, and Colon, rectum, and anus $(6.8 \%)$ cancers. Conclusion: The findings in this study are salient and have potential to serve as important information for the National Cancer Control Program to formulate prevention and control strategies.
\end{abstract}

Keywords: Cancer incidence and mortality- cancer epidemiology- population based cancer registry- Myanmar

Asian Pac J Cancer Prev, 23 (1), 311-318

\section{Introduction}

According to the report published by world health organization (WHO) in 2018, non-communicable diseases (NCDs) accounted for 41 million of the world's 57 million deaths (71\%) in 2016. Among these deaths, 15 million of those were premature and occurred in the age group of 30 to 70 . The burden is greater in low- and middle- income countries as $78 \%$ of all NCD deaths and $85 \%$ of premature deaths occurred in these countries (WHO, 2018). Cancer is the first or second leading cause of premature death in the age group of 30 to 69 in 134 of 183 countries, and third or fourth in an additional 45 countries (Wild et al., 2020). In Myanmar, NCDs were estimated to account for $68 \%$ of all deaths. Among NCDs, cancers contributed to proportional mortality of $13 \%$ in 2016 (WHO, 2016).

Global Cancer Observatory estimated 69,554 new cancer cases and 51,059 cancer deaths occurred in
Myanmar in 2018. The top five most common cancers were Lung, Stomach, Cervix uteri, Breast and Liver in both sexes, Lung, Stomach, Liver, Oesophagus, and Colorectum in Males and Cervix uteri, Breast, Lung, Stomach, and Colorectum in Females. Age-standardized incidence rates (World) were 141.9 for males and 123.7 for females. Regarding mortality, the top 5 cancer deaths are cancers of the Lung, Cervix uteri, Stomach, Breast, and Liver (Ferlay et al., 2020).

In Myanmar, strengthening and improving cancer registries are priority actions for evidence-based national cancer control planning (Singh et al., 2017). The Program of Action on Cancer Therapy (PACT) of International Atomic Energy Agency (IAEA) in collaboration with WHO and International Agency for Research on Cancer (IARC) visited Myanmar in 2015 and found that cancer registration was the top priority for Myanmar and acknowledged cancer registration activities were being

${ }^{1}$ Nay Pyi Taw Cancer Registry, Nay Pyi Taw General Hospital (1000 Bedded), Department of Medical Services, Ministry of Health, Myanmar. ${ }^{2}$ Department of Oncology, No.2 Defense Services General Hospital (1000 Bedded), Nay Pyi Taw, Ministry of Defense, Nay Pyi Taw, Myanmar. ${ }^{3}$ Vital Registration Unit, Central Statistical Organization, Ministry of Planning and Finance, Nay Pyi Taw, Myanmar.*For Correspondence: drkmshwe1977@gmail.com 
developed in Nay Pyi Taw. They recommended starting Population Based Cancer Registries (PBCR) in the Nay Pyi Taw Union Territory as the first step and then expanding to other States and Regions in the future to set up PBCR (IAEA, 2018). Myanmar is a partner country of the Global Initiative for Cancer Registry Development which provides capacity building across the field of cancer registration through technical support, training, advocacy, and networking through IARC regional hubs for the planning and development of PBCRs in Myanmar (IARC, 2020). The Collaborative Research Agreement (CRA) between IARC and the Ministry of Health of Myanmar commenced in 2017 aims to support sustainable improvements in the quality, scope, and use of populationbased cancer registry data in Myanmar (IARC, 2017).

\section{Materials and Methods}

Nay Pyi Taw is the capital of the Republic of the Union of Myanmar which is at the center of the country where all government offices (ministries) are located. Regarding cancer treatment, Nay Pyi Taw General Hospital (1000-Bedded) is the major hospital for cancer treatment in this region and provides diagnostic facilities like nuclear medicine and diagnostic radiology and therapeutic facilities like radiotherapy and chemotherapy. Data collection is mainly active by visiting registry staffs to all hospitals and laboratories of Nay Pyi Taw Union Territory and vital registration unit of Central Statistical Organization for death certificate data. The registry team also collected the data form Yangon General Hospital, Mandalay General Hospital, Yangon children hospital and Mandalay children hospital for the data of some cancer patients from Nay Pyi Taw who got the cancer treatments at there. The collected data are recorded in compliance with the International Classification of Coding of Diseases for Oncology-3rd edition (ICD-0-3) coding rules (Fritz et al., 2000). Multiple primary tumors were defined and recorded according to IARC-IACR guidelines (Working group Report, 2005). The data are stored in CanReg5 and checked for consistency and duplications are performed (Ervik, 2020).
The data were analyzed by the $\mathrm{R}$ software featured by CanReg5. The results were presented as number of cases by site, sex, and age, cumulative risk (CR), crude rate, age-specific, and age-standardized incidence rates (ASRs) per 100,000 . The ASR was calculated by direct methods according to world standard population (Doll et al., 1966). The population denominator used to calculate the rates were based on the 2014 Myanmar population and housing census. The population beyond 2014 was estimated and reported by the Department of Population of the Ministry of Labour, Immigration and Population, Myanmar (Ministry of Labour, Immigration and Population, 2017) and we used these population figures for calculation of rates.

\section{Results}

Demography of nay pyi taw union territory

The area of Nay Pyi Taw Union Territory is 70,571 $\mathrm{km} 2$ in 2 Districts and 8 Townships. According to the 2014 census, the total population for Nay Pyi Taw Union Territory was $1,160,242$ persons which represented 2.3 percent of the total population of Myanmar. Of these, 565,155 were males $(48.71 \%)$ and 595,087 (51.29\%) were females. The sex ratio was 95 males per 100 females. It ranked thirteenth in population size when compared with other States/Regions in the country. Urban population was 375,189 (32\%) while rural population was 785,053 (68\%). The population pyramid for Nay Pyi Taw Union Territory in 2014 shows a near-stationary type of population structure with almost equal distribution of age groups below 30 years. A large proportion of the population in the Nay Pyi Taw Pyramid was in the economically active age groups (15-64), of which majority of them are of ages between 15 and 39 (Ministry of Immigration and Population, 2015).

\section{The most common cancers by sex}

Between 2013 and 2017, 5,952 cancer cases were registered of which 2,835 were males and 3,117 were females. In both sexes combined, Lung cancer was the most common (14\%), followed by Breast (11.4\%), Liver
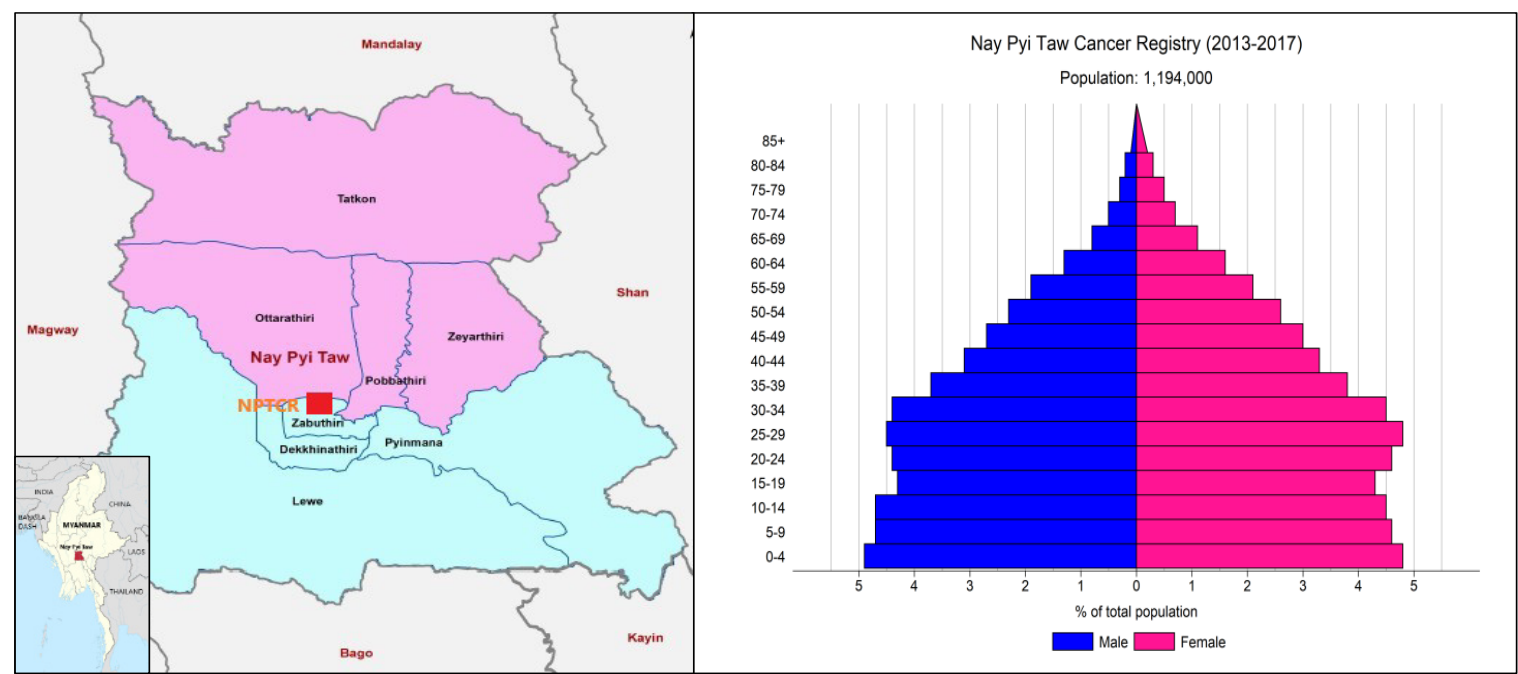

Figure 1. Geographical Map and Estimated Average Annual Population 

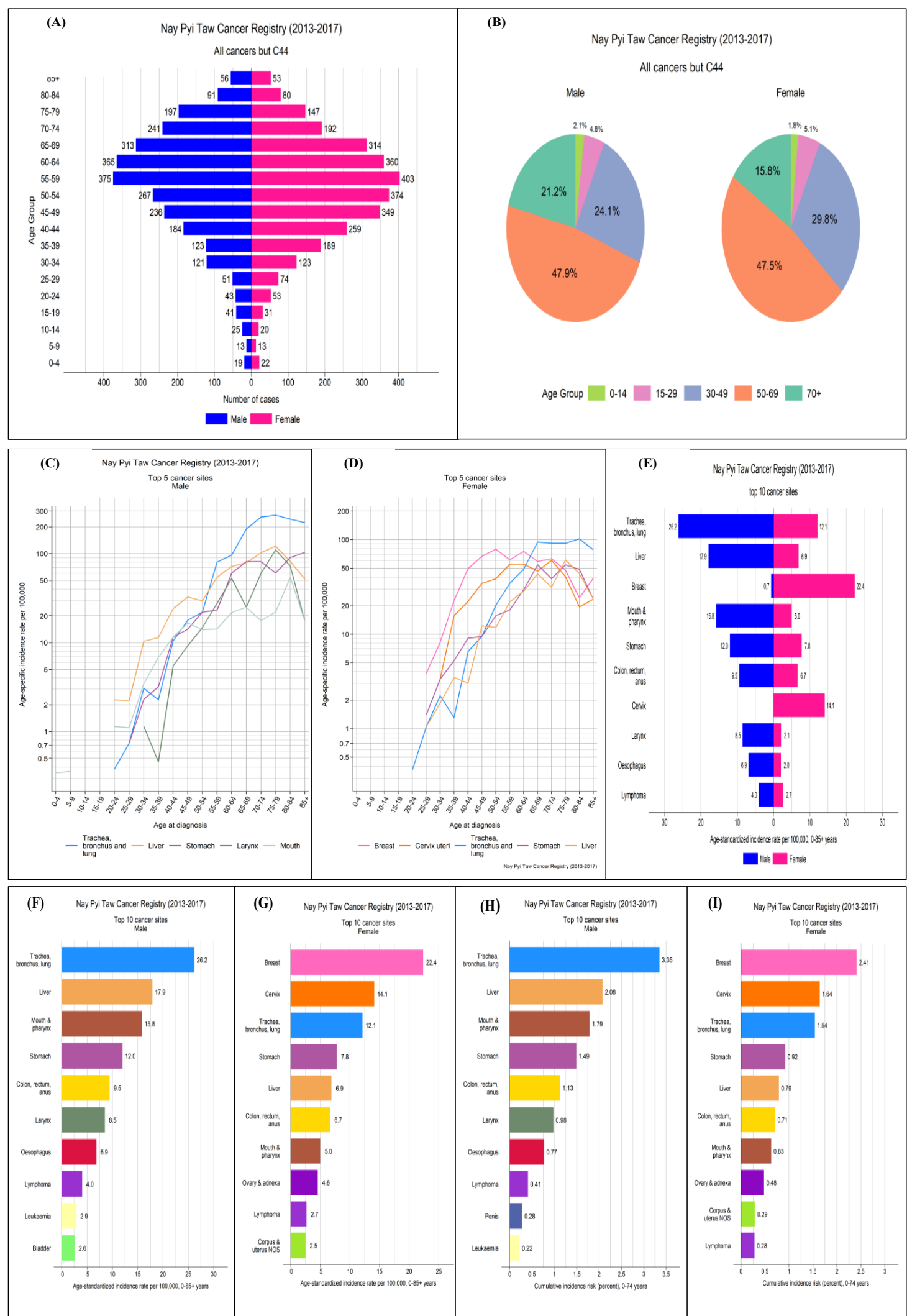

Figure 2. Patterns and Trends of Cancer in the Five Year Period 2013-2017. A, number of cases in period by age group and sex; B, Pie chart, distribution of cases by age group and sex; C, Age-specific incidence rates of top 5 cancer sites in Male; D, Age-specific incidence rates of top 5 cancers in Female; E, ASRs of top 10 cancers (Both sexes); F, Top 10 cancers ASR in Male; G, Top 10 cancers ASR in Female; H, Top 10 cancers, cumulative risk, 0-74 years in Male; I, Top 10 cancers, cumulative risk, 0-74 years in Female

(10.2\%), Mouth and Pharynx (8.5\%), Stomach (7.8\%), Cervix (6.8\%), Colon, Rectum, and Anus (6.8\%), Larynx (4.0\%), Oesophagus (3.3\%) and Lymphoma (3.0\%). Overall, the top ten cancer types accounted for $75.8 \%$ of the total newly diagnosed cancer cases. The average ages (in years) for the top 10 cancer types were 63.1 (Lung), 51.7 (Breast), 55.8 (Liver), 54.6 (Mouth and Pharynx), 58.6 (Stomach), 54 (Cervix), 56.1 (Colon, Rectum, 
Table 1. Top 10 Cancers in Males

\begin{tabular}{llccccc}
\hline Sr No & Types of cancers & $\begin{array}{c}\text { Number of } \\
\text { patients (n) }\end{array}$ & $\begin{array}{c}\text { Percentage of all } \\
\text { male cancers (\%) }\end{array}$ & $\begin{array}{c}\text { Crude Rate } \\
\text { Risk (CR) }\end{array}$ & $\begin{array}{c}\text { Cumulative } \\
\text { RSR }\end{array}$ \\
\hline 1 & Lung & 512 & 18.1 & 17.5 & 3.35 & 26.2 \\
2 & Liver & 419 & 14.8 & 14.3 & 2.08 & 17.9 \\
3 & Mouth \& Pharynx & 369 & 13 & 12.6 & 1.79 & 15.8 \\
4 & Stomach & 251 & 8.9 & 8.6 & 1.49 & 12 \\
5 & Colon, Rectum and Anus & 209 & 7.4 & 7.2 & 1.13 & 9.5 \\
6 & Larynx & 182 & 6.4 & 6.2 & 0.98 & 8.5 \\
7 & Oesophagus & 141 & 5.0 & 4.8 & 0.77 & 6.9 \\
8 & Lymphoma & 103 & 3.6 & 3.5 & 0.41 & 4.0 \\
9 & Leukaemia & 84 & 3.0 & 2.8 & 0.22 & 2.9 \\
10 & Penis & 57 & 2.0 & 2.0 & 0.28 & 2.4 \\
\hline
\end{tabular}

and Anus), 60.5 (Larynx), 62.4 (Oesophagus) and 41.6 (Lymphoma) respectively. Top 10 cancers in Males and Females were shown in Table 1 and 2. Total ASR for all male new cancer cases cases was 125.9 and 107.3 for all new female cancer cases excluding non-melanoma skin cancer.
Cancer mortality

Total number of deaths in Nay Pyi Taw Union Territory during the research period was 23,429 of which $1,874(8 \%)$ people died from various forms of cancer. Among these cancer deaths, the most common cancer for both sexes combined was Liver $(20.8 \%)$ followed by Lung (15.7\%), Mouth and Pharynx (9.3\%), Stomach

Table 2. Top 10 Cancers in Females

\begin{tabular}{llccccc}
\hline Sr No & Types of cancers & Number of patients (n) & $\begin{array}{c}\text { Percentage of all } \\
\text { female cancers (\%) }\end{array}$ & $\begin{array}{c}\text { Crude } \\
\text { Rate }\end{array}$ & $\begin{array}{c}\text { Cumulative } \\
\text { Risk (CR) }\end{array}$ & $\begin{array}{c}\text { ASR } \\
\text { (CR }\end{array}$ \\
\hline 1 & Breast & 661 & 21.2 & 21.4 & 2.41 & 22.4 \\
2 & Cervix & 406 & 13 & 13.2 & 1.64 & 14.1 \\
3 & Lung & 321 & 10.3 & 10.4 & 1.54 & 12.1 \\
4 & Stomach & 216 & 6.9 & 7 & 0.92 & 7.8 \\
5 & Colon, Rectum and Anus & 195 & 6.3 & 6.4 & 0.71 & 6.7 \\
6 & Liver & 190 & 6.1 & 6.2 & 0.79 & 6.9 \\
7 & Ovary & 136 & 4.4 & 4.4 & 0.48 & 4.6 \\
8 & Mouth \& Pharynx & 134 & 4.3 & 4.3 & 0.63 & 5.0 \\
9 & Lymphoma & 77 & 2.5 & 2.3 & 0.28 & 2.7 \\
10 & Corpus Uteri & 69 & 2.2 & 2.2 & 0.29 & 2.5 \\
\hline
\end{tabular}

\begin{tabular}{|c|c|c|c|c|c|c|c|c|c|c|c|c|}
\hline \multicolumn{2}{|r|}{$\mathrm{ICCC} 3$} & \multirow[b]{2}{*}{$0-4$} & \multicolumn{4}{|c|}{ Number of cases } & \multirow[b]{2}{*}{$\begin{array}{c}\% \\
\text { total } \\
\end{array}$} & \multirow[b]{2}{*}{$0-4$} & \multicolumn{3}{|c|}{ Rates per million } & \multirow[b]{2}{*}{ ASR } \\
\hline & & & $5-9$ & $10-14$ & All & $\mathrm{M} / \mathrm{F}$ & & & $5-9$ & $10-14$ & crude & \\
\hline & All & 41 & 26 & 47 & 114 & 1.1 & 100.0 & 71.5 & 46.8 & 85.7 & 67.9 & 67.6 \\
\hline I & Leukaemias & 14 & 13 & 11 & 38 & 1.2 & 33.3 & 24.4 & 23.4 & 20.1 & 22.6 & 22.8 \\
\hline II & Lymphomas & 5 & 5 & 8 & 18 & 1.0 & 15.8 & 8.7 & 9.0 & 14.6 & 10.7 & 10.5 \\
\hline III & CNS neoplasms & 1 & 2 & 6 & 9 & 2.0 & 7.9 & 1.7 & 3.6 & 10.9 & 5.4 & 5.0 \\
\hline IV & Neuroblastoma & 2 & 0 & 0 & 2 & 1.0 & 1.8 & 3.5 & 0.0 & 0.0 & 1.2 & 1.4 \\
\hline IX & Soft tissue sarcomas & 2 & 0 & 3 & 5 & 4.0 & 4.4 & 3.5 & 0.0 & 5.5 & 3.0 & 2.9 \\
\hline V & Retinoblastoma & 5 & 1 & 0 & 6 & 1.0 & 5.3 & 8.7 & 1.8 & 0.0 & 3.6 & 4.0 \\
\hline VI & Renal tumors & 2 & 0 & 0 & 2 & 0.0 & 1.8 & 3.5 & 0.0 & 0.0 & 1.2 & 1.4 \\
\hline VII & Hepatic tumors & 1 & 0 & 1 & 2 & 0.0 & 1.8 & 1.7 & 0.0 & 1.8 & 1.2 & 1.2 \\
\hline VIII & Malignant bone tumors & 0 & 1 & 4 & 5 & 0.2 & 4.4 & 0.0 & 1.8 & 7.3 & 3.0 & 2.7 \\
\hline$x$ & Germ cell tumors & 0 & 1 & 3 & 4 & 0.0 & 3.5 & 0.0 & 1.8 & 5.5 & 2.4 & 2.2 \\
\hline XI-XII & Other & 9 & 3 & 11 & 23 & 1.1 & 20.2 & 15.7 & 5.4 & 20.1 & 13.7 & 13.6 \\
\hline
\end{tabular}

Figure 3. The Incidence of Childhood Cancer, Classified According to the International Classification of Childhood Cancer (ICCC-3). (Steliarova-Foucher et al, 2005) 


\begin{tabular}{|c|c|c|c|c|c|c|}
\hline & & & MALE & & & \\
\hline SITE & Cases & $\%$ Total & ASR(se) & $M V(\%)$ & CLIN(\%) & $\mathrm{DCO}(\%)$ \\
\hline Mouth \& pharynx & 368 & 12.98 & $15.85(0.87)$ & 98.37 & 0.00 & 1.63 \\
\hline Oesophagus & 141 & 4.97 & $6.89(0.60)$ & 97.16 & 0.00 & 2.84 \\
\hline Stomach & 251 & 8.85 & $12.05(0.79)$ & 83.27 & 0.00 & 16.73 \\
\hline Colon, rectum, anus & 209 & 7.37 & $9.49(0.70)$ & 86.60 & 0.00 & 13.40 \\
\hline Liver & 419 & 14.78 & $17.95(0.92)$ & 6.68 & 51.79 & 41.53 \\
\hline Pancreas & 24 & 0.85 & $1.05(0.23)$ & 37.50 & 62.50 & 0.00 \\
\hline Larynx & 182 & 6.42 & $8.55(0.66)$ & 76.37 & 0.55 & 23.08 \\
\hline Trachea, bronchus, lung & 512 & 18.06 & $26.23(1.20)$ & 23.83 & 59.38 & 16.80 \\
\hline Melanoma of skin & 3 & 0.11 & $0.17(0.10)$ & 100.00 & 0.00 & 0.00 \\
\hline Breast & 15 & 0.53 & $0.65(0.17)$ & 100.00 & 0.00 & 0.00 \\
\hline Prostate & 33 & 1.16 & $2.04(0.36)$ & 87.88 & 0.00 & 12.12 \\
\hline Testis & 14 & 0.49 & $0.45(0.12)$ & 100.00 & 0.00 & 0.00 \\
\hline Kidney \& urinary NOS & 27 & 0.95 & $1.27(0.25)$ & 96.30 & 0.00 & 3.70 \\
\hline Bladder & 53 & 1.87 & $2.57(0.38)$ & 96.23 & 0.00 & 3.77 \\
\hline Brain \& central nervous system & 36 & 1.27 & $1.37(0.24)$ & 63.89 & 19.44 & 16.67 \\
\hline Thyroid & 12 & 0.42 & $0.39(0.12)$ & 100.00 & 0.00 & 0.00 \\
\hline III-defined & 79 & 2.79 & $3.52(0.42)$ & 27.85 & 37.97 & 34.18 \\
\hline Lymphoma & 105 & 3.70 & $4.13(0.43)$ & 92.38 & 7.62 & 0.00 \\
\hline Leukaemia & 84 & 2.96 & $2.91(0.33)$ & 80.95 & 5.95 & 13.10 \\
\hline All sites but $\mathrm{C} 44$ & 2762 & 97.43 & $125.92(2.52)$ & 61.44 & 22.48 & 16.08 \\
\hline \multicolumn{7}{|c|}{ FEMALE } \\
\hline SITE & Cases & $\%$ Total & ASR(se) & $M V(\%)$ & CLIN(\%) & $\mathrm{DCO}(\%)$ \\
\hline Mouth \& pharynx & 134 & 4.30 & $5.00(0.44)$ & 91.04 & 0.00 & 8.96 \\
\hline Oesophagus & 58 & 1.86 & $2.03(0.27)$ & 96.55 & 0.00 & 3.45 \\
\hline Stomach & 216 & 6.93 & $7.79(0.54)$ & 80.09 & 0.00 & 19.91 \\
\hline Colon, rectum, anus & 195 & 6.26 & $6.66(0.49)$ & 83.59 & 0.00 & 16.41 \\
\hline Liver & 190 & 6.10 & $6.90(0.51)$ & 6.84 & 46.84 & 46.32 \\
\hline Pancreas & 31 & 0.99 & $1.16(0.21)$ & 51.61 & 48.39 & 0.00 \\
\hline Larynx & 55 & 1.76 & $2.09(0.29)$ & 58.18 & 0.00 & 41.82 \\
\hline Trachea, bronchus, lung & 321 & 10.30 & $12.15(0.69)$ & 15.89 & 58.88 & 25.23 \\
\hline Pleura \& other thoracic & 4 & 0.13 & $0.19(0.10)$ & 100.00 & 0.00 & 0.00 \\
\hline Melanoma of skin & 1 & 0.03 & $0.02(0.02)$ & 100.00 & 0.00 & 0.00 \\
\hline Breast & 661 & 21.21 & $22.43(0.89)$ & 92.59 & 0.00 & 7.41 \\
\hline Cervix & 406 & 13.03 & $14.15(0.72)$ & 90.15 & 0.00 & 9.85 \\
\hline Corpus \& uterus NOS & 69 & 2.21 & $2.49(0.31)$ & 59.42 & 0.00 & 40.58 \\
\hline Ovary \& adnexa & 136 & 4.36 & $4.59(0.40)$ & 81.62 & 15.44 & 2.94 \\
\hline Kidney \& urinary NOS & 14 & 0.45 & $0.55(0.15)$ & 92.86 & 0.00 & 7.14 \\
\hline Bladder & 25 & 0.80 & $0.99(0.20)$ & 96.00 & 0.00 & 4.00 \\
\hline Brain \& central nervous system & 35 & 1.12 & $1.15(0.20)$ & 48.57 & 31.43 & 20.00 \\
\hline Thyroid & 35 & 1.12 & $1.04(0.18)$ & 97.14 & 0.00 & 2.86 \\
\hline III-defined & 90 & 2.89 & $3.20(0.35)$ & 26.67 & 40.00 & 33.33 \\
\hline Lymphoma & 78 & 2.50 & $2.71(0.31)$ & 78.21 & 21.79 & 0.00 \\
\hline Leukaemia & 70 & 2.25 & $2.32(0.28)$ & 77.14 & 7.14 & 15.71 \\
\hline All sites but C44 & 3056 & 98.04 & $107.26(1.98)$ & 71.04 & 13.81 & 15.15 \\
\hline
\end{tabular}

Figure 4. Data Quality Indicators in Male and Female Cancers

(7.5\%), Colon, Rectum, and Anus (6.8\%) respectively. Overall, the top ten cancer deaths contributed to $80.3 \%$ of all cancer deaths in both sexes combined.

By sex, liver cancer was the leading cause of cancer deaths in males (27\%), followed by Lung (18.4\%), Mouth and Pharynx (11.4\%), Stomach (7.9\%), and Colon, Rectum and Anus (6.1\%). Among females, Liver cancer was again the leading cause of cancer deaths (14.2\%), followed by Lung (12.8\%), Breast (11.5\%), Cervix (10.3\%), and Colon, Rectum and Anus (7.3\%).

\section{Discussion}

The cancer statistics including cancer incidence and mortality data estimated by population-based cancer registry are crucial in development and evaluation of strategies for cancer prevention and control policies (Parkin DM, 2006). The National Health Plan (2017-2021) of Myanmar recognizes NCDs as a public health priority. Furthermore, one of the National Strategic Plans for prevention and control NCDs is to develop a comprehensive and sustainable surveillance system. To set up and develop high-quality regional PBCRs based in public cancer treating hospitals is one strategy of the National Cancer Control Plan (Ministry of Health, 2017). This first five consecutive years' report provides descriptive analysis of data (five consecutive years) for all cancer sites of the first PBCR in Myanmar.

The total number of new cancer cases in Nay Pyi Taw Union Territory was steadily increasing in every year between 2013 and 2017. This increasing incidence trends were observed especially in the top five cancers. 
We expect the total number of new cancer cases could be rising in the future due to more and more completeness of the registry and possible nationwide cancer screening programs in the country. The number of new cancer cases increased with age starting from 30 and decreased after 69. It is probably because life expectancy at birth in Myanmar is 64.7 in both sexes, 60.2 in males and 69.3 in females (Ministry of Labour, Immigration and Population, 2016).

Overall, one in every seven men and one in every eight women of Nay Pyi Taw residents are likely to develop cancer in his or her life before the age of 75. The top five cancers which present the highest lifetime risks were lung ( 1 in 30), liver ( 1 in 48), mouth and pharynx ( 1 in 56), stomach (1 in 67), and colon, rectum and anus (1 in 88) for males while breast ( 1 in 41), cervix (1 in 61), lung (1 in 65), stomach (1 in 108), and liver (1 in 125) for females.

Tobacco related cancers identified by the IARC monograph include cancers of the lung, oral cavity, nasal cavity, and paranasal sinuses, nasopharynx, oropharynx, hypopharynx, larynx, esophagus, stomach, pancreas, liver, kidney (body and pelvis), ureter, urinary bladder, cervix, and myeloid leukemia (Cogliano et al., 2011). In this study, we found tobacco-related cancers contributed $70.6 \%$ of all male cancer cases, $48.1 \%$ of all female cancer cases, and $58.8 \%$ of all cases in both sexes combined. Lung cancer is the leading cause of cancer incidence in both sexes combined (rates 38.3 per 100,000) and in males (rates 26.2 per 100,000$)$. Regarding mortality, it is the second leading cause of cancer deaths in both sexes after liver cancers. The findings in this study is alarming and pointing to speed up implementing tobacco control strategies and policies to prevent the burden of tobacco-related cancers.

Globally, it is estimated that 2.2 million new cancer cases (one in eight) are related to infections in 2018. Infections-related cancers include carcinoma of the oral cavity, oropharynx including tonsil and base of tongue, larynx, anal squamous cell carcinoma, cervix, vulva, vagina, penis, adult T-cell leukemia and lymphoma, Kaposi sarcoma, Hodgkin lymphoma, Burkitt lymphoma, nasopharyngeal carcinoma, gastric carcinoma, gastric non-Hodgkin lymphoma, Hepatocellular carcinoma, cholangiocarcinoma and bladder (de Martel et al., 2020). In this study, infections-related cancers contributed to $41.9 \%$ for all new cancer cases in both sexes combined with $48.7 \%$ in males and $35.8 \%$ in females, respectively. Liver cancer is the top cancer among all infectious related cancers. It is also the second most common cancer in both sexes combined (rates 24.8 per 100,000) and in males (rates 17.9 per 100,000) and it is the first leading cause of cancer deaths in both sexes combined. Myanmar has been an endemic country for viral hepatitis for many years. Around 3.3 million people are living with viral hepatitis $\mathrm{B}$ and approximately 1.3 million people are living with viral hepatitis C (Ministry of Health, 2017). Under the Expanded Program of Immunization (EPI), coverage of nationwide immunization for HBV at birth was 14\% and childhood was 91\% in 2019 (Sandhu et al., 2020). Myanmar's hepatitis control program is providing freeof-charge viral hepatitis $\mathrm{C}$ treatment at 12 public hospitals in 8 different states and regions starting in 2017 (Scott et al., 2021). Therefore, primary prevention through Human
Papilloma Virus (HPV) vaccination and expanding the availability of HPV and HCV treatments in the country would lead to prevent people from liver cancers as well as significant reduction in liver cancers related deaths in the future.

In 2018, GLOBOCAN estimated cervical cancer was the leading site of cancer incidence $(A S R=21.5$, Cumulative risk $\%$ at 75 years old $=2$ ) among females and the first leading cause of female cancer deaths in Myanmar. It is the second leading cause of cancer-related deaths after lung cancer in both sexes combined (Arbyn et al., 2020). In this study, we found that cervical cancer ranked at the seventh position among the most common cancers in both sexes combined and the second position in females' cancers after breast cancer with $\mathrm{ASR}=14.1$ and cumulative risk of 1.64. Regarding mortality. It is the eighth leading cause of cancer death in both sexes combined and the fourth in female. The Ministry of Health of Myanmar, with the support from Gavi (the Vaccine Alliance), launched the HPV immunization program of in 2020 and started vaccinating the girls between 9 and 10 years old in the country (Bruni et al., 2019). Thus, the future generation of girls will be protected from HPV attributable cancers, including cervical cancer in Myanmar.

Pediatric cancers contributed to $2.1 \%$ in males and $1.9 \%$ in females for all new cancer cases for the age group between 0 and 14 . The most common cancers in this age group were Leukemia $(33.3 \%, \mathrm{ASR}=22.8)$, Lymphoma $(15.8 \%, \mathrm{ASR}=10.5)$ and CNS neoplasms $(7.9 \%, \mathrm{ASR}=5.0)$. The overall ASR was 67.6 per million children and the highest age-specific incidence rate was observed for children aged 10-14 years (85.7 per million). Top childhood common cancers in this study are consistent with those findings of international childhood cancer study (Steliarova-Foucher et al, 2017).

The ASRs of all cancers sites in this study were $119.4 / 100,000$ in both sexes combined, 129.3/100,000 in males, and 109.5/100,000 in females. This is lower than that reported in GLOBOCAN estimates in 2018 for Myanmar which were 130.9/100,000 in sexes combined, $141.9 / 100,000$ in males, and 123.7/100,000 in females. As there are no country specific data sources, GLOBOCAN estimates for Myanmar were extrapolated from cancer registries of neighboring countries mainly from India and Thailand (Ferlay et al (2019). That is why cancer incidence and mortality patterns of the top common cancer sites in both sexes, males and females differ from those found in this study.

Comparability, validity, timeliness, and completeness are four important indicators of data quality in cancer registration (Bray F and Parkin DM 2009). Although Nay Pyi Taw Cancer Registry comply with the IACR's guidelines and procedures of cancer, the validity of the data, especially the proportion of morphologically verified cases (MV \%,) and the proportion of Death Certificate Only (DCO \%) have some issues. In this study, $\mathrm{MV} \%$ is 61.44 in males and 71.04 in females, and DCO \% is 16.08 in males and 15.15 in females. The MV\% largely depends on the most common cancers, service delivery practice of health care facilities, and hospital information system used in the region. The most common cancers in this study are 
Lung and Liver cancers and getting biopsy is difficult in those kinds of cancers. In addition, the use of electronic Health Management Information system (e-HMIS) in every public hospital hampers the possibility of getting a much better MV\% (Ministry of Health, 2017). This system is designed to assess aggregate health data and it is very difficult to record diagnosis methods and morphology of each cancer type of individual cancer patients. Although the verbal autopsy process to identify the cause of death for community deaths has already been in place since 2016 in some regions of Myanmar to improve the quality of cause of death information, the completeness of death registration was critically low which is less than $60 \%$ (Oung et al, 2017).

In conclusion, a significant proportion of tobacco-related and infection-related cancers were found in this study. The findings in this study are salient and have potential to serve as important information for the National Cancer Control Program of Myanmar. Patterns of cancer incidence and mortality estimates in Globocan are inconsistent with the findings in our subnational available data. Therefore, population-based cancer registries are urgently needed in Myanmar not only to improve the accuracy of Globocan estimates according to actual cancer situations of the country but also for the monitoring and evaluation of cancer control policies and cancer actions of Ministry of Health.

\section{Authors Contribution Statement}

Kaung Myat Shwe: Responsible for all registry operations, collection and analysis of data, preparation, drafting, editing of the article and final reporting. Soe Myat Win: Responsible for all registry operations, collection and analysis of data. Aye Nyein Thant, Aung Myo Sat Htay and Hlwan Moe Han: Data collection. Naw Hsah Ka Paw: Data collection for mortality statistics.

\section{Acknowledgments}

Special thanks go to Dr. Myint Htwe, Former Union Minister of the Ministry of Health and Sports, Dr. Kyaw Kan Kaung Deputy Director-General of the Non-communicable Disease Control Division of the Department of Public Health, Professor Soe Aung President of the Myanmar Oncology Society, and the officials from Nay Pyi Taw General Hospital (1,000 Bedded), Department of Medical services and Department of Medical Research for their support to the work of Nay Pyi Taw Cancer Registry. The authors wish to thank officials and staffs of medical records departments from all hospitals and laboratories of Nay Pyi Taw, Yangon and Mandalay General Hospital, Yangon and Mandalay Children Hospitals, Public health unit of Nay Pyi Taw Council and Vital Registration Section of the Central Statistical Organization for sharing the data. The Nay Pyi Taw Cancer Registry also acknowledges the WHO, IAEA, IARC, IACR, GICR and IARC Regional Hub (Mumbai), National Cancer Institute (Thailand), Chiang Mai Cancer Registry, Lampang Cancer Registry and National Cancer Center of Japan for the technical help and kind support for all registration activities in Myanmar.

\section{Funding statement}

Nay Pyi Taw Cancer Registry got initial financial support from IARC under collaborative research agreement (CRA No. CSU / 17 /15) for sustainable improvements in the quality, scope and use of populationbased cancer registry data in Myanmar. This study was supported by Implementation Research Grant 2018-2019 (Project ID-105) from Ministry of Health and Sports.

\section{Ethical Approval}

This study was approved by Ethic Review Committee of the University of Medicine (1), Yangon. Myanmar.

\section{Data availability statement}

This study was not registered in any registering dataset. All data generated or analyzed during this study are in the custody of the researchers and will be made available upon request.

\section{Conflict of Interest}

The authors declare that they have no competing interests.

\section{References}

Arbyn M, Weiderpass E, Bruni L, et al (2020). "Estimates of incidence and mortality of cervical cancer in 2018: a worldwide analysis. Lancet Glob Health, 8, e191-e203

Bray F, Parkin DM (2009). Evaluation of data quality in the cancer registry: principles and methods. Part I: comparability, validity and timeliness. Eur J Cancer, 45, 747-55.

Bruni L, Albero G, Serrano B, et al (2019). ICO/IARC Information Centre on HPV and Cancer (HPV Information Centre). Human Papillomavirus and Related Diseases in Myanmar. Summary Report 17 June 2019. [Accessed on December 2020]

Cogliano VJ, Baan R, Straif K, et al (2011). Preventable exposures associated with human cancers. J Natl Cancer Inst, 103, 1827-39.

de Martel C, Georges D, Ferlay J, Bray F, Clifford GM (2020). Global burden of cancer attributable to infections in 2018: a worldwide incidence analysis. Lancet Global Health, 8 , $180-90$

Doll R, Payne P, Waterhouse JAH (1966). Cancer incidence in five continents: a technical report. Genève, International Union against Cancer.

Ervik MJ (2020). CanReg5-Instructions.pdf. International Agency for Research on Cancer.

Ferlay J, Colombet M, Soerjomataram I, et al (2019). Estimating the global cancer incidence and mortality in 2018: GLOBOCAN sources and methods. Int J Cancer, 144, 1941-53.

Ferlay J, et al (2020). "Global Cancer Observatory: Cancer Today.” Lyon, France: International Agency for Research on Cancer. Available from: https://gco.iarc.fr/today, accessed [10 June 2021].

Fritz A, et al (2013). International classification of diseases for oncology: ICD-O, 3rd edn. First Revision. Geneva: World Health Organization.

International Agency for Research on Cancer (2017). Biennial Report 2016-2017 < Section of Cancer Surveillance (CSU): 7-12, IARC Publications. Lyon, France.

Asian Pacific Journal of Cancer Prevention, Vol 23 
International Agency for Research on Cancer (2020). Global Initiative for Cancer Registry development." Retrieved 20 April, 2021, from https://gicr.iarc.fr/gicr-partner-countries/ International Atomic Energy Agency (2018). "Myanmar's Renewed Focus on National Cancer Care and Control Services." Retrieved 23 May, 2021, from https://www. iaea.org/ newscenter/news/myanmars-renewed-focus-onnational-cancer-care-and-control services

Ministry of Health (2017). Myanmar National Action Plan for Viral Hepatitis Response 2017-2020.pdf. Department of Public Health. The Republic of the Union of Myanmar.

Ministry of Health (2017). National Strategic Action Plans for Prevention and Control of NCDs (2017-2021).pdf. Department of Public Health Non-communicable Diseases Control Unit. Ministry of Health. The Republic of the Union of Myanmar.

Ministry of Health (2017). Public Health Statistics (2014-2016). pdf, Department of Public Health. Ministry of Health. The Republic of the Union of Myanmar.

Ministry of Immigration and Population (2015). 2014 Myanmar Population and Housing Census A Changing Population-. Nay Pyi Taw Union Territory Figures at a Glance. Department of Population. The Republic of the Union of Myanmar.

Ministry of Labour, Immigration and Population (2016). THEMATIC REPORT ON MORTALITY.pdf. Department of Population. The Republic of the Union of Myanmar.

Ministry of Labour, Immigration and Population (2017). THEMATIC REPORT ON POPULATION PROJECTIONS FOR THE UNION OF MYANMAR, STATES/REGIONS, RURAL AND URBAN AREAS, 2014 - 2050.pdf. Department of Population. The Republic of the Union of Myanmar.

Parkin DM (2006). The evolution of the population-based cancer registry. Nat Rev Cancer, 6, 603-12.

Sandhu HS, Roesel S, Sharifuzzaman M, Chunsuttiwat S, Tohme RA.(2020). Progress toward hepatitis B control - South-East Asia Region, 2016-2019. MMWR Morb Mortal Wkly Rep, 69, 988-92.

Scott N., et al (2021). Hepatitis C elimination in Myanmar: Modelling the impact, cost, cost-effectiveness and economic benefits.Lancet Reg Health West Pac, 10, 100129.

Singh T, Pearlman PC, Kostelecky B (2017). Supporting Evidence-Based National Cancer Control Planning: The Asia-Pacific Phase II Leadership Forum. J Cancer Policy, 12, $75-8$.

Steliarova-Foucher E, Stiller C, Lacour B, Kaatsch P (2005). International Classification of Childhood Cancer, third edition. Cancer, 103, 1457-67.

Steliarova-Foucher E, Colombet M, Ries LAG, et al (2017). International incidence of childhood cancer, 2001-10: a population-based registry study. Lancet Oncol, 18, 719-31.

Tin Oung M, Richter K, Prasartkul P, Tangcharoensathien V (2017). Myanmar mortality registration: an assessment for system improvement. Population Health Metrics, 15, 34.

Wild CP, Weiderpass E, Stewart BW (2020). World Cancer Report: Cancer Research for Cancer Prevention. Lyon, France, International Agency for Research on Cancer.

Working Group Report (2005). International rules for multiple primary cancers (ICD-0 third edition). Eur J Cancer Prev, 14, 307-8.

World Health Organization (2016). Myanmar NCDs profile.pdf. Geneva, World Health Organization.

World Health Organization (2018). Global Status Report on Noncommunicable Diseases COUNTRY PROFILES 2018. pdf. Geneva. World Health Organization.

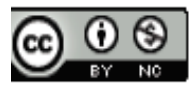

This work is licensed under a Creative Commons AttributionNon Commercial 4.0 International License. 